\title{
El arte del retrato en los textos periodísticos de Manuel Chaves Nogales
}

\section{Erretratuaren artea Manuel Chaves Nogalesen egunkari-testuetan}

\section{The Portrait Art in Manuel Chaves Nogales}

\author{
Álvaro Pérez Álvarez ${ }^{1}$ \\ Antonio Martínez Illán²
}

\section{zer}

Vol. 21 - Núm. 40

ISSN: $1137-1102$

e-ISSN: 1989-631X

DOI: $10.1387 /$ zer. 15513

pp. $219-236$

Recibido el 18 de febrero de 2016, aceptado el 10 de mayo de 2016.

\section{Resumen}

Este artículo estudia el arte de la caracterización del periodista Manuel Chaves Nogales (Sevilla, 1897 - Madrid, 1944) en una selección de sus textos periodísticos publicados en España. Se trata de 18 piezas de diferentes géneros (crónicas, semblanzas, reportajes, entrevistas) en los que la caracterización es elemento central. A través de ellos se puede observar la evolución en la caracterización de Chaves y su afán por desvelar el carácter de personajes de actualidad a través de escenas significativas, mediante unas pocas pinceladas que, indirectamente, muestran sus preocupaciones políticas, sociales y periodísticas.

Palabras clave: Chaves Nogales, retrato, periodismo, biografía, perfil, II República.

\section{Laburpena}

Artikulu honek Manuel Chaves Nogales (Sevilla, 1897 - Madril, 1944) kazetariaren karakterizazio-artea aztertzen du, Espainian argitaratutako bere egunkari-testu batzuk oinarritzat hartuta. Zenbait generotako (kronikak, azalpenak, erreportajeak, elkarrizketak) 18 pieza dira, eta horietan karakterizazioa da funtsezko elementua. Horien bitartez, Chaves Nogalesen karakterizazioak izan duen bilakaera ikus daiteke, baita eszena esanguratsuen bitartez gaurkotasuneko pertsonaien izaera erakusteko bere ahalegina ere. Zeharka bada ere, bere politika, gizarte eta egunkari arloko kezkak islatzen ditu pintzelkada gutxi batzuen bitartez.

Gako-hitzak: Chaves Nogales, erretratua, kazetaritza, biografia, perfila, II. Errepublika.

\footnotetext{
Universidad de Montevideo, maperez1@um.edu.uy

2 Universidad de Navarra, amartinez@unav.es
} 


\begin{abstract}
This article studies the characterization art in a selection of newspaper articles written by the Spanish journalist Manuel Chaves Nogales (Seville, 1897 - Madrid, 1944). Specifically, the investigation analyzes 18 pieces of different genres (chronicles, portraits, interviews) where the character is essential. Through them you can see the evolution in the characterization of Chaves, his quest to reveal the character of people in the news through meaningful scenes by a few strokes that indirectly show their political, social and journalistic concerns.
\end{abstract}

Keywords: Chaves Nogales, portrait, journalism, biography, Spanish II Republic. 


\section{Introducción}

La introducción de la biografía en el periodismo fue un proceso natural. El periodismo responde al quién, está en su misma naturaleza preguntarse por las personas y sus acciones. Desde este punto de vista, "el periodismo también contribuye a identificar los objetivos de una comunidad, y reconocer sus héroes y villanos" (Kovach y Rosentiel, 2012: 24). Busca mostrar a esas personas tal y como son, ya sea como objeto o sujeto de interés, o como participante o protagonista de una acción social porque "si echamos la vista atrás, trescientos o tres mil años, comprobaremos que resulta imposible disociar información de comunidad" (Kovach y Rosentiel, 2012: 32).

Dentro del género biográfico, y por cuestiones formales y de extensión, el periodismo se nutre sobre todo del retrato. El periodismo es una disciplina retratista en el sentido de que describe personas, escenarios y hechos reales. Los autores seleccionan un personaje, se acercan a él para entrevistarlo y poder escribir sobre él de primera mano, como testigos directos. Lo específico del periodismo es la brevedad, el instante. La escritura periodística debe captar la esencia de una persona partir del entramado de una entrevista o de un encuentro. Se busca el testimonio real, la actualidad, el momento, lo periodístico: "Los retratos literarios responden a la demanda de los lectores de la prensa periódica: la de acceder a la vida o a la personalidad de los autores que admiran. Gracias al retrato, el escritor deja de ser un nombre, en la de portada de un libro, para convertirse en algo más próximo al lector" (Celma Valero, 1999: 30).

Los años 20 y 30 del siglo XX han sido definidos como un periodo editorial de "moda biográfica" (Serrano, 2002; Pulido, 2009) al que los periodistas no fueron ajenos. De hecho, aportaron parte de su oficio a la escritura biográfica. François Dossel ha estudiado esta relación entre la biografía y el periodismo en Francia, abordando el caso de las biografías de Jean Lacouture, periodista y escritor francés (Dossel 2007: 94-104). Weinberg lo ha hecho en Estados Unidos, analizando el caso de las biografías nacidas a partir de reportajes. Lo que él denomina short-form biography o periodical profile (Weinberg 1992: 156). En España existen estudios sobre la semblanza, el perfil o la necrológica que serían los géneros periodísticos de contenido biográfico (De Rosendo, 2010; Gómez, 2011).

En este contexto, esta investigación estudia la manera de retratar en prensa utilizada por Manuel Chaves Nogales (Sevilla, 1897 - Madrid, 1944), "el primer periodista-literato del siglo XX" (Cintas, 2001: 98) o "el periodista puro" (Carabias, 1969: 326). Y, en concreto, se centra en el período correspondiente a la labor periodística de Chaves en España, antes de su exilio: desde sus inicios en la prensa andaluza (1918) hasta su etapa como subdirector del diario Ahora y el comienzo de la Guerra Civil (1936). Para delimitar el estudio de toda su obra periodística durante esos años, se han escogido determinados textos incluidos en su Obra periodística donde la caracterización es central, a pesar de que no siempre se trate de semblanzas y estemos, en algunos casos, ante entrevistas, crónicas y reportajes. Se trata sobre todo de observar la posible evolución en su manera de caracterizar y las constantes que presentan estos textos, no los rasgos en cuanto a su género.

Leer los textos de Chaves enseña que en el centro de toda información hay siempre un protagonista, una vida. Serían paradigmáticas sus nueve historias de A sangre 
y fuego escritas en París tras su exilio sobre personajes de la Guerra Civil a los que da, como dice en la nota, "una existencia real y una personalidad auténtica" (Chaves Nogales, 2000: 33). En un momento periodístico y social de cambios, Chaves puso el foco en lo esencial del periodismo: comprender la realidad presupone comprender a sus actores y el contexto en el que actúan, de ahí el interés de observar su manera de caracterizar a los protagonistas de la información. El objetivo último de esta investigación es desvelar los rasgos retratísticos en la obra de Chaves a partir de la siguiente hipótesis: Chaves no hablaba de ideologías, ni de movimientos sociales, sino de personas que vivían dentro de esas realidades y las encarnaban. Y entendía que solo a través del retrato de quiénes eran protagonistas se podía entender el mundo convulso que les rodeaba.

\section{Metodología}

Para analizar los textos seleccionados, se van a observar cuatro procedimientos caracterizadores:

1. Cuestiones formales y de contenido. Se señalarán aspectos lingüísticos, retóricos o narrativos que permiten entender la escritura periodística como la manera en que se dirigía a sus lectores y con qué tono definía a los protagonistas-.

2. Los procedimientos que De Rosendo (2010: 158-175) señala para caracterizar un personaje en un perfil. Por un lado, los procedimientos básicos: utilizar una definición totalizadora para describir al personaje, utilizar demostraciones inductivas y deductivas, o acudir al relato de una acción exenta de interpretación, a través de la cual el lector debe sacar sus propias conclusiones, la etopeya y la prosopopeya.

3. Los procedimientos secundarios: la individualización del personaje a través de su tipificación o singularidad dentro de un colectivo, la perspectiva global del personaje, y la construcción de una trayectoria -si hay o no evolución en su carácter, cómo se ha producido ese cambio, de dónde partía y adónde ha llegado, etc.- - Como se verá, estos procedimientos no son independientes, y unos métodos pueden ir ligados a otros, complementándose a través de la mirada del periodista, que se encarga de dar coherencia al personaje.

4. Dado que el objeto de estudio no se reduce a perfiles o semblanzas, se observará también la influencia del escenario y de la historia en las personas y el carácter mostrado mediante la acción.

5. Además, se acudirá a las consideraciones que, sobre el periodismo, Chaves escribió o dijo (Chaves Nogales, 1925, 1929, 2000; Pérez, 2013a), para cotejar hasta qué punto siguió su doctrina: contar, relatar y reseñar con el objetivo de mover al lector a la reflexión desde la actualidad. Se observará a este respecto la cercanía de Chaves con la información, si emitía o no juicios directos, y la finalidad o función de sus escritos. 
Debe dejarse constancia de que, por ser textos de géneros distintos y en etapas diferentes de su trayectoria, es de suponer que su desarrollo estuviese condicionado no solo por el buen hacer de Chaves, sino también por cuestiones relativas al trabajo periodístico: desde la urgencia con la que se escribían hasta el espacio del que disponía el redactor; quizá en su etapa de formación contase apenas con una columna mientras que en su fase de director de Ahora, por ejemplo, podría disponer de más espacio, de textos acompañados de fotografías, etc.

Teniendo en cuenta estas cuestiones, y tras leer toda su obra, se han seleccionado 18 ejemplos significativos pertenecientes a diferentes géneros que se han agrupado por temas y momento de publicación en cinco bloques:

1. Dos semblanzas publicadas en la serie "Andalucía y sus hombres", aparecidas en 1918 en El Noticiero Sevillano que muestran al joven Chaves, aún en Andalucía.

2. Sus crónicas-reportajes ganadoras del premio Mariano de Cavia sobre la aviadora Ruth Elder, escritas en 1927 para Heraldo de Madrid, que marcan su reconocimiento nacional.

3. Su reportaje sobre el rey afgano Amanullah, publicado en la revista $E s$ tampa en 1929.

4. Su artículo sobre Hitler, “Adolfo I, Emperador" y su entrevista a Goebbels, ¿Habrá fascismo en España?”, publicados también en Ahora en 1933.

5. Por último, su crónica sobre la situación de Haile Selassie, el Negus, emperador de Etiopía, tras su exilio en 1936, aparecida de nuevo en Ahora.

Esta selección es representativa porque, en primer lugar, cubre toda la etapa periodística de Chaves en España. En segundo lugar, se trata de piezas de diferentes géneros (semblanzas, crónicas-reportajes, entrevistas) donde la caracterización es central. La variedad de personalidades que retrata muestra una idea de Chaves sobre lo que su oficio perseguía en última instancia. Objetivo que expresa como reflexión en su prólogo de A sangre y fuego tras verse obligado a exiliarse de España: "Avivar el espíritu de mis compatriotas y suscitar en ellos el interés por los grandes temas de nuestro tiempo (Chaves, 2000, 25).

\section{2. “Andalucía y sus hombres” en El Noticiero Sevillano, mayo de 1918}

Chaves realizó dos semblanzas breves, sin fotografía, dentro de la serie "Andalucía y sus hombres" de El Noticiero Sevillano. La primera, el 8 de mayo de 1918, se dedicaba al abogado y pedagogo Manuel Siurot. La segunda, el 17 del mismo mes, tenía como protagonistas a los hermanos Quintero, Serafín y Joaquín, escritores especializados en comedias teatrales. Ambas se titulaban con el nombre de los protagonistas: "Manuel Siurot" y "S. y J. Álvarez Quintero". 
Chaves no necesita presentar a los personajes porque los considera conocidos. En el caso de Siurot, alude a su popularidad: "Siempre requerido y excusándose siempre, Manuel Siurot aparece de vez en cuando ante los telones de nuestra actualidad y en la crónica, la conferencia o el discurso hace vibrar la nota halagüeña de su personalidad inconfundible" ". Pese a no haberlo tratado en persona, especula sobre su forma de ser, le intuye "instintivamente", "una conformación espiritual más andaluza que la de casi todos nuestros hombres"4 y le considera un ejemplo. Apela a la intuición, y también a las grandes palabras. El estilo de su primera juventud es quizá más grandilocuente y adjetivado, si se permite la expresión, de lo que lo será en el futuro. Así se observa en determinados pasajes: “¡oh, la triste fecundidad de nuestra raza!", "que la salva de nuestra juventud dé vida a nuestras ciudades, y el vigor de nuestros brazos arranque a nuestra propia tierra sus riquezas..."5, etc.

En cuanto a los hermanos Quintero, el periodista los caracteriza atribuyéndoles un andalucismo inequívoco desde el arranque de la pieza:

Ausentes de su región durante los años de lucha en un ambiente extraño, y desconociendo cómo se desenvolvía nuestra vida ciudadana, del mismo modo que para nosotros eran desconocidos, en lo esencial, sus vacilaciones y sus triunfos, los hermanos Quintero han sabido conservar siempre en toda su pureza y religiosidad el amor a la región ${ }^{6}$.

Ese es el rasgo que mejor les define, el que les singulariza:

Han sabido, a despecho de todos, mantenerse en el torreón de su andalucismo, aun durante los años en que, para triunfar nuestros hombres, abandonaban sus hogares y en su éxodo habían de renegar de su patria y sus amores, cuando la condición de andaluz era lo suficiente para ser tenido en menosprecio ${ }^{7}$.

Y, a partir de esta reflexión y de la valía de los hermanos Quintero, Chaves habla de la necesidad de evitar a los jóvenes andaluces la inmigración. Una aspiración que, sin embargo, no se cumplió en su caso, pues tuvo que partir hacia Madrid para crecer y ser reconocido en su profesión.

Estas dos piezas muestran a un periodista que está formándose aún como reportero, da una definición totalizadora de los personajes, no hay demostración ni escenas. En esta clase de textos, construidos a partir de documentos de archivo, "el periodista tiene un amplio margen de iniciativa y, aunque recurra a una fuente de información común como son los archivos, tiene una mayor disposición a la hora de tratar los temas que son de su interés" (Marín, Caminos, Armentia y Alberdi, 2003: 16). Desde este punto de vista, Chaves ofrece una mirada en la que el personaje es también un

\footnotetext{
3 CHAVES NOGALES, Manuel. “Andalucía y sus hombres. Manuel Siurot”. En: El Noticiero Sevillano, 8 de mayo de 1918 .

4 Ibídem.

5 Ibídem.

6 CHAVES NOGALES, Manuel. “Andalucía y sus hombres. S. y J. Álvarez Quintero”. En: El Noticiero Sevillano, 17 de mayo de 1918.

7 Ibídem.
} 
cauce para hablar de temas de actualidad que le preocupan, en este caso la situación y el futuro de Andalucía: no interesan los personajes, sino lo que representan. Se buscan modelos "nacionales" o regionales. La función aquí es más didáctica que informativa y sus opiniones no siempre se basan en hechos sino en intuiciones.

Quizá por todo ello, estos primeros textos los escribe todavía sin cumplir uno de los rasgos que dotarían a sus retratos de mayor carácter: el trato directo con los protagonistas de la información. Chaves ofrece una voz más periodística (cada vez menos valorativa y más informativa) y un sello característico cuando se involucra con los personajes de sus piezas. Fue así, de hecho, como obtuvo el premio Mariano de Cavia, con su artículo sobre Ruth Elder.

\section{3. "La aviadora Ruth Elder", en Heraldo de Madrid, octubre de 1927}

Chaves escribió en octubre de 1927 una serie de artículos dedicados a la aviadora estadounidense Ruth Elder. La aviadora, que partió de Nueva York, logró cruzar el Atlántico y aterrizar en Lisboa, y hasta allí se desplazó Chaves para informar de su aventura. Heraldo de Madrid publicó la información entre los días 25 y 28 de octubre. Un año después de su publicación, el periodista obtendría el premio Mariano de Cavia por este trabajo. Todas las informaciones aparecieron acompañadas de fotografías, la mayor parte de ellas anónimas, aunque la del día 27, tomada en Getafe, estaba firmada por Luque. En total, fueron ocho las imágenes en las que aparecía Elder, ya fuese sola, en dos ocasiones, o acompañada de su compañero de vuelo, o de autoridades portuguesas o españolas. En ellas se reflejaban escenas de los honores y agasajos que recibió la aviadora por su hazaña. En una de esas imágenes, aparece también el autor del texto como muestra de lo cerca de la noticia que llegó a estar. La inclusión de fotografías en los diarios y revistas, de la que Chaves fue testigo en los años 20, obligó a los textos apoyarse en estas imágenes y también a contar aquello que la fotografía no podía contar.

Los artículos sobre Ruth Elder giran en torno a la hazaña de la aviadora, debido en parte a la popularidad de la aviación en aquella época. De ahí también la duración del reportaje: el tema era capaz de mantener el interés de los lectores durante días. Como explicaba Chaves, "poco a poco los periódicos de todo el mundo, poblados siempre de reseñas y noticias de los grandes vuelos, han ido infiltrando en las gentes esa curiosidad"». Además, el atractivo informativo de la aviadora como personaje era indudable.

La finalidad del texto era, pues, entretener al lector. No debe pasarse por alto que la pieza fue publicada en un momento de censura informativa, debido a la dictadura encabezada por Miguel Primo de Rivera que imperaba en España. Chaves eligió un tema de contenido político neutro, pero de actualidad informativa, ameno y capaz de generar interés entre los lectores.

Para explicar el logro concreto de Elder, Chaves describe el carácter y las motivaciones de la aviadora, una mujer "en cuya graciosa figura de girl ultramoderna se concentra la atención universal"9 debido, a juicio de Chaves, a que reunía tres rasgos

${ }^{8}$ CHAVES NOGALES, Manuel. "La emocionante partida de un hidroavión que va a cruzar el Atlántico". En: Heraldo de Madrid, 25 de octubre de 1927.

9 CHAVES NOGALES, Manuel. "Ruth Elder, la hermosísima aviadora norteamericana que estuvo a 
atractivos para el lector: era una mujer, era hermosa, y estaba loca, de una manera, eso sí, convencional, vistiendo trajes de hombre, bailando el charlestón, cortándose el pelo muy corto, a la moda europea, etc.

Según contaba Chaves en el reportaje, la aviadora apenas se dirigía a los periodistas porque había vendido la exclusiva de su viaje a una agencia periodística estadounidense. A juicio del periodista, la aviadora se había equivocado: "Lo interesante no son las impresiones de ella, sino la impresión que ella produce" ${ }^{10}$. Pese a la exclusividad de la agencia americana, Chaves consiguió que Elder le firmase un autógrafo saludando al pueblo español y pudo tratarla de cerca: fue testigo directo de la información que relataba, practicaba el periodismo de andar y contar que defendía. Así, acudía a la prosopografía para describir a la aviadora como un mujer "delgada, esbelta, ojos verdes, entre maliciosos e ingenuos, cara fina, sonriente, ondas negras [...] lo mejor suyo es su constante inmovilidad, llena de gracia"11; en otra pieza insistía en su belleza: "Maravilla en ella, más que nada, su fragilidad, su inconsistencia [...], es el arquetipo de la belleza nueva". Por este motivo, para Chaves, estaba alejada de la belleza clásica y puede incluso permitirse "no tener manos": "Los brazos y las manos de Elder son feos: brazos y manos deformados de muchacho aprendiz de chofer. Como si no los tuviese" ${ }^{12}$. Chaves incidía en la belleza de la aviadora, por tanto, no solo para describirla sino para explicar el porqué de su popularidad. El físico de Elder arrojaba una clave interpretativa, si no fuese tan bella, carecería de interés, o así lo consideraba el periodista. Se trataba de descripciones inductivas pero también deductivas que ayudaban a mostrar quién era en realidad la aviadora.

Chaves individualiza a Elder como una persona de atractivo excepcional para el lector pues encarnaba un nuevo tipo de mujer. Se conjugaban en ella la actualidad del personaje con su interés para el lector, dos de las características habituales en los textos de géneros retratísticos publicados en prensa en aquella época. Chaves siente que tiene autoridad para hacerse cargo de quién es esa mujer y contar su percepción sobre ella dado que la conoció en persona, algo que será constante en su obra. Recurre a la demostración y no a la descripción totalizadora porque entiende que, como periodista, tiene la obligación de hacer ver los rasgos que sirven de base a sus apreciaciones, para que los lectores las comprendan y sientan que forman parte del proceso caracterizador. El interés del personaje, en cualquier caso, era relativo, se debía a la opinión del periodista, al medio y, en este caso, a la necesidad de hacer al personaje interesante en un momento de dictadura y censura que limitaba las posibilidades temáticas.

punto de perecer en la travesía del Atlántico ha llegado a Lisboa esta tarde a las cinco". En: Heraldo de Madrid, 25 de octubre de 1927.

${ }^{10}$ CHAVES NOGALES, Manuel. "Esta tarde ha llegado a Madrid, en un avión Junker, la célebre aviadora Ruth Elder, acompañada de un redactor de Heraldo, único periodista español que ha volado con ella desde Portugal". En: Heraldo de Madrid, 27 de octubre de 1927.

${ }^{11}$ CHAVES NOGALES, Manuel. "Ruth Elder, la hermosísima aviadora norteamericana que estuvo a punto de perecer en la travesía del Atlántico ha llegado a Lisboa esta tarde a las cinco". En: Heraldo de Madrid, 25 de octubre de 1927.

${ }^{12}$ CHAVES NOGALES, Manuel. "Esta tarde ha llegado a Madrid, en un avión Junker, la célebre aviadora Ruth Elder, acompañada de un redactor de Heraldo, único periodista español que ha volado con ella desde Portugal". En: Heraldo de Madrid, 27 de octubre de 1927. 
En estos textos Chaves no solo habla de Elder. Coincidiendo con su estancia en Lisboa, tres aviadores (el piloto Mertz, el radiotelegrafista Bock y el mecánico Rhode) iban a emprender otra hazaña aérea, en dirección opuesta a la de Elder: cruzar el Atlántico partiendo desde Lisboa hacia América. Chaves les incluyó en el reportaje y trazó un "silueta" física y psicológica de cada uno de ellos, acudiendo a los mitos y los arquetipos: Mertz tenía "una figurilla exigua y un aire sutil y equívoco de japonés" y era "uno de esos tipos extraños creados por la guerra"; Bock era un "honrado hombre de labor diaria que sabe bien su oficio y pone su experiencia, penosa y lentamente adquirida, al servicio de esta intentona heroica" y el mecánico Rhode era "el hombre en estado de naturaleza. De vivir en la edad mitológica no hubiera habido más héroe que él"13. De estos hombres se espera solo la hazaña, son personajes de una gesta heroica, por lo que cada uno de ellos se limitaba a cumplir su función: el periodista les había conocido y por eso podía decir que cada uno estaba en su papel y detectaba en ellos un interés complementario al del personaje principal de la información, por eso merecían un retrato de grupo.

\section{4. "Amanullah, el rey que ha perdido su corona por amar demasiado a su pueblo", en Estampa, 13/VV/1929}

Chaves escribió también reportajes de actualidad que necesitaban un contexto histórico para explicarse. En ellos, investigaba la historia de un lugar o de un personaje para dar el contexto de la información. Así, por ejemplo, en el reportaje "Amanullah, el rey que ha perdido su corona por amar demasiado a su pueblo", aparecido en Estampa el 13 de junio de 1929, Chaves introdujo el texto con unos pasajes sobre el pueblo y la historia afgana, antes de hablar del personaje principal: Amanullah Kan, el rey del país que en el momento de la publicación del artículo libraba una lucha por el poder.

Para ilustrar el texto, aparecen siete fotografías: dos que tienen a Amanullah como protagonista (un retrato del rey afgano y una reunión con su consejo de ministros, que muestra al rey ejerciendo sus obligaciones), dos dedicadas a otros protagonistas de la historia (la esposa del rey y su enemigo político Bacha Sakao), tres imágenes de soldados desconocidos (un retrato de un soldado anónimo defensor de Amanullah, y dos retratos corales de las tropas en conflicto, como acompañamiento del relato principal) y, por último, una fotografía en la que se aprecia la única línea de ferrocarril que existía en Afganistán, promovida por Amanullah.

Chaves reconstruyó la vida de Amanullah antes de la guerra con detalle: "Se levantaba a las siete de la mañana, daba un paseo a caballo y ponía mano a su tarea diaria de rey. Era a la vez rey y presidente del Consejo"14; habló de sus aficiones: "Amanullah dividía el tiempo que le dejaban libre sus tareas de rey entre el estudio y los deportes"15 y también de sus logros: "Había tenido que crearlo todo, carreteras, ejército, escuelas, explotaciones industriales y agrícolas; [...] había introducido en el

\footnotetext{
${ }^{13}$ CHAVES NOGALES, Manuel. "La emocionante partida de un hidroavión que va a cruzar el Atlántico". En: Heraldo de Madrid, 25 de octubre de 1927.

${ }^{14}$ CHAVES NOGALES, Manuel. "Amanullah, el rey que ha perdido su corona por amar demasiado a su pueblo". En: Estampa, 13 de junio de 1929.

${ }^{15}$ Ibídem.
} 
Afganistán el sistema métrico decimal, el telégrafo y los automóviles"16, antes de explicar la pérdida de su poder. La comprensión de las dimensiones privada y pública del rey afgano ayudaba a hacerse cargo del personaje en su totalidad. Además, Chaves comenzaba a mostrar escenas cotidianas, aunque fuesen del pasado, acudiendo a una técnica que desde los años 50 se encargó de popularizar el Nuevo Periodismo estadounidense (Pérez, 2013b). Ya no es una descripción estática, el protagonista actúa y sus actos hablan de cómo es.

Pero, más allá de la rutina de Amanullah, un suceso extraordinario cambió el devenir de los acontecimientos y marcó su evolución como personaje, el deseo del rey afgano de introducir aún más avances similares a los de los pueblos occidentales en su país tras un viaje por Europa: "Se equivocó. El pueblo afgano, que le ayudó a sacudir el yugo de Inglaterra, le miraba a él también como a un extranjero en cuanto quiso poner mano sobre las bárbaras costumbres, la inmoralidad administrativa y los prejuicios religiosos de sus súbditos", aseguraba Chaves. La historia de Amanullah era la historia de una "patética lucha" de un rey que perdió su corona "por procurar el bienestar de su pueblo"17.

Este texto es un ejemplo del periodismo de Chaves: el periodista es un testigo directo que emite juicios solo si están justificados por los hechos, sin alejarse de la información, pero en textos abiertos a la función explicativa e interpretativa.

Chaves juzgaba lo que veía, la vida de Amanullah solo podía entenderse en relación con su país y con sus decisiones políticas. Aparece ya aquí una idea que está en muchos de sus textos: la vocación como configuradora de la realidad privada, el trabajo como instrumento de realización personal y la coherencia con la actividad individual como manera de alcanzar la plenitud. En otras palabras, la vocación personal configuraba la trayectoria de los personajes. Esta idea de Chaves es la que vertebra la que para muchos es su obra maestra, la biografía Juan Belmonte, matador de toros, publicada por entregas en Estampa en 1935.

En este primer periodo, por tanto, se observa una evolución: Chaves parte del estilo y la finalidad ejemplarizante del siglo XIX pero gracias a la labor y técnicas periodísticas (estar allí, preguntar, identificar qué puede interesar a los lectores en ese momento concreto de la actualidad) en sus retratos empieza a aparecer la demostración, la vida privada y el relato de las costumbres. Además, comienza a darse cuenta de qué pinceladas son imprescindibles en un buen retrato. También de que hay personajes que solo precisan de un bosquejo y otros de mucho detalle, según el papel que desempeñan en el relato principal

\section{5. “¿Habrá fascismo en España?” y “Adolfo I, emperador”, en Ahora, $21 / \mathrm{V} / 1933$ y $28 / \mathrm{V} / 1933$}

El cambio político que se vivió en España desde 1931 no fue obstáculo para que Chaves siguiese con atención los sucesos europeos. Así, dentro de su serie de reportajes titulados "Cómo se vive en los países de régimen fascista", escribió una entrevista a Goebbels y una pieza dedicada a Adolf Hitler para el diario Ahora.

\footnotetext{
${ }^{16}$ Ibídem.

17 Ibídem.
} 
La entrevista a Goebbels apareció publicada el 21 de mayo de 1933. En ella, Chaves interrogaba al ministro de Propaganda nazi, con algunas restricciones que se explican al comienzo del texto:

He ofrecido hacerlo y lo cumplo. Cuando solicité una interviú con el doctor Goebbels, que es, a mi juicio, el tipo más interesante de la nueva Alemania -incluyendo en esta subordinación de interés al propio Hitler-, me pusieron, naturalmente, algunas cortapisas. Ser ciudadano de la República Española y periodista liberal no es hoy, para los gobernantes alemanes, una invitación a la confianza. Los españoles estamos haciendo exactamente lo contrario de lo que hacen los alemanes, y ya suponen ellos que no vamos a traicionar nuestras convicciones nacionales en beneficio de las suyas. El señor Ministro de Propaganda -me dijeron- contestará a tres preguntas que usted le haga, pero, si no quiere correr el riesgo de ser desautorizado, estas tres preguntas y sus respuestas deben publicarse textualmente, sin comentarios ni interpretaciones; cada pregunta, con su respuesta, a renglón seguido. Nada más. Así lo prometí y así lo cumplo ${ }^{18}$.

Aunque en apariencia cumplía el requisito que le había sido impuesto, se permitió añadir, al margen de la entrevista, sus impresiones sobre el lugarteniente de Hitler que hacen cambiar el sentido de las palabras del dirigente alemán: "Permítaseme, sin embargo, decir a mis lectores quién es este doctor Goebbels. Es un tipo ridículo, grotesco; con su gabardinita y su pata torcida, se ha pasado diez años siendo el hazmerreír de los periodistas liberales [...]. Siendo, como es, el azote de los judíos, se ha dicho incluso que era judío, aunque, según parece, la única verdad es que su suegra llevaba un apellido israelita"19. Chaves es capaz de ver cómo era, de hacer notar su peligro. Así, relaciona su manera de comunicarse con su ideología, su actitud personal con su intransigencia política:

Es un tipo enconado, duro, implacable [...]. Goebbels escribía como hablaba: claro, sucinto, terminante. Hay en él la misma capacidad de sugestión y de dominio que en todos los grandes iluminados, en todos esos tipos nazarenoides de una sola idea encarnizada: Robespierre o Lenin. Lucirá mucho menos que Hitler en las paradas, pero es más certero. Creo que no se pone nunca la camisa parda, pero debajo de su gabardinita insignificante lleva la guerrera más ajustada de Alemania. Es de esa estirpe dura de los sectarios, de los hombres votados a un ideal con el cual fusilan a su padre si se les pone por delante. En España no ha habido así más que algunos curas carlistas, hace ya muchos años ${ }^{20}$.

Esta visión, de nuevo, mezcla prosopografía y etopeya, construye a partir de un rasgo físico un perfil psicológico. Además, acercaba al personaje a la sociedad española, en primer lugar para explicar su radicalismo, y en segundo lugar para comparar los sistemas políticos de ambos países. De nuevo, el periodista explica al personaje

\footnotetext{
${ }^{18}$ CHAVES NOGALES, Manuel. “¿Habrá fascismo en España?”. En: Ahora, 21 de mayo de 1933.

19 ' bídem.

${ }^{20}$ Ibídem.
} 
en relación a su momento histórico. En ese despiece previo a la entrevista está el verdadero retrato de Goebbels, un hombre condicionado por su físico, radical e "iluminado". Tal vez por su sevillanismo o por su senequismo (Carabias, 1969), Chaves tenía el talento de ver al personaje en un rasgo sin caer en la caricatura.

La entrevista al político alemán, pese a no haber podido ser editada, sirve para confirmar las ideas de Chaves: el tono y el contenido de las respuestas hablan del carácter intransigente de Goebbels. Así, afirmaba que "los judíos residentes en Alemania tienen obligación de evitar que el país donde viven sea difamado" ${ }^{21}$, y anunciaba a Chaves: "Tengo, eso sí, el convencimiento de que la transformación espiritual de Europa, expresada en el fascismo, el kemalismo y el nacionalsocialismo, será completa dentro de una o dos décadas. Cada pueblo deberá encontrar en la esencia de su propia personalidad nacional nuevas formas para dicho espíritu" 22 . El valor de la pieza se encuentra no solo en la descripción del mandatario nazi, sino también en lo premonitorio de las palabras de Goebbels. Como explica Muñoz Molina,

Chaves Nogales es una persona que ve y que mira lo que tiene delante de los ojos, lo que muchísima gente no ha querido ver o no ha sabido ver [...]. Pero ese ver a Goebbels, esa capacidad de ver y no solo juzgar lo que te dice sino también cómo es el personaje que te lo dice, eso es un talento asombroso (Suberviola; Torrente, 2013: 30).

El periodista dibujó también, a partir de su viaje a Alemania y de la observación de su cultura, el perfil del Führer. De manera inductiva, mostraba que los alemanes eran, a su juicio, un pueblo monárquico: Alemania necesitaba un rey. "Y, ante esa necesidad -explicaba Chaves-, se ha fabricado un rey a su medida, a su imagen y semejanza; un rey que ha pasado hambre y ha sido obrero y sin trabajo y ha hecho la guerra en las trincheras, un rey con gabardina, Adolfo I, emperador"23. El periodista crea una metáfora y una imagen que justifica y desarrolla en el texto. Para explicar a Hitler, necesita explicar antes el contexto en el que surge.

El mérito de Hitler, su gran fuerza, fue "la resurrección de los ideales imperialistas" "24. Amparado en ellos, su ascenso fue imparable: se trataba de la consecuencia de la forma de ser del pueblo alemán. Durante los años de la República de Weimar los alemanes añoraban a su "Landvater", a un padre de la patria. Según Chaves, "el alemán, en ese pacto que hace espiritualmente con su príncipe, tiene como base de su ciega supeditación un concepto patriarcal y democrático de la existencia; cada cual cumple su deber; el emperador, mandando; el soldado, obedeciendo". Explica el carácter alemán a través de Hitler y puede hacerlo porque sus reportajes y viajes le avalan.

Hitler, "este 'pintorcillo de puertas' -como le llamaba Stresemann-", ese "célibe" que no parecía "dispuesto a sacrificar su soltería por fundar una dinastía imperial" 25 , adoptó el papel de emperador. Pero, se preguntaba el periodista, ¿por qué Hitler y

\footnotetext{
${ }^{21}$ Ibídem.

${ }^{22}$ Ibídem.

${ }^{23}$ CHAVES NOGALES, Manuel. “Adolfo I, emperador". En: Ahora, 28 de mayo de 1933.

${ }^{24}$ Ibídem.

${ }^{25}$ Ibídem.
} 
no otro político fue el que consiguió liderar al pueblo alemán? Por la fantasía que había creado: "Hitler ha podido decir al pueblo alemán, verdad o mentira: 'El nacionalsocialismo no es un partido más; es una Weltanschauung, una concepción del Universo'. Con esto, que bien puede ser un camelo, Hitler ha hecho un imperio"26. Chaves le atribuye la capacidad de liderar gracias a su propuesta no solo política sino vital. Los alemanes necesitaban tener un motivo, necesitaban escuchar que no eran menos que nadie. Hitler arrastraba multitudes porque supo conectar con el pueblo, supo decirles, tal y como muestra Chaves, lo que querían oír. El mérito de este análisis está, como casi siempre en los artículos de Chaves, en haberlo realizado en el mismo momento en que se estaba produciendo, y en saber ver qué tenía delante y vislumbrar la esencia del personaje en unas pocas palabras. En eso consiste, de hecho, hacer un retrato. El periodista, en todo caso, no se dejó embaucar por los postulados hitlerianos:

No hay que despistarse; de verdad, de verdad, Hitler no era más que un pintor que no sabía pintar, un artista sin talento. Como no acertó a pintar un cuadro discreto, se tuvo que poner a construir un imperio [...]. Será todo lo que quiera: líder, Führer, canciller, regente, emperador; pero la verdad de su alma es que lo que él quería ser era pintor y no tuvo talento bastante para serlo ${ }^{27}$.

E insistía en el escaso talento de Hitler:

Cada vez se ve con más claridad que para esta faena de gobernar dictatorialmente los pueblos no son precisas unas dotes excepcionales [...]. Ahora resulta que no; que un señor con gabardina que no acierta a pintar un cuadro decorosamente, puede, merced a unas circunstancias providenciales, convertirse en uno de los seres señeros de la Humanidad; el mismo caso se ha repetido ya en Rusia, donde unos teorizantes mediocres han construido un formidable imperio, y en Italia, donde un periodista amanerado ha puesto en pie un país. Hay que pensar que las dictaduras favorecen el encumbramiento de las medianías, de los señores discretos con gabardinas ${ }^{28}$.

Chaves recurre a los fracasos de la vida privada para explicar las actitudes en la vida pública, como había hecho con Goebbels. En estas páginas sobre los líderes nazis el periodista ofrece una caracterización de personajes con tres ideas destacadas. En primer lugar, Hitler no sabe pintar y su frustración por no tener talento le lleva a querer levantar un imperio. Goebbels es un hombre acomplejado, que fue el "hazmerreír de los periodistas liberales" durante años. Las frustraciones y las tendencias más profundas explican las acciones. La prosopografía es clave para definir a estos dos políticos.

En segundo lugar, Chaves se considera capacitado para interpretar y sacar conclusiones porque se ha documentado, ha hablado con ellos (en el caso de Goebbels) y su experiencia profesional le ha permitido conocer el alma humana. El hecho de ser

\footnotetext{
${ }^{26}$ Ibídem.

27 Ibídem.

${ }^{28}$ Ibídem.
} 
extranjeros, y por tanto no tan conocidos para el pueblo español, hace que la interpretación explícita de Chaves en estas piezas sea más comprensible o tolerable. Era 1933 y Chaves ya advertía del peligro de Hitler, de la posibilidad de que convirtiese a Alemania en una nueva Rusia, aunque de signo opuesto y, además, acertó en sus pronósticos.

Por último, la capacidad de observación, la agudeza en su análisis y la detección de los complejos personales de los líderes del nazismo, en apenas 500 palabras, confirmaban el sexto sentido periodístico de Chaves, su facilidad para detectar en la actualidad los fenómenos clave y a los personajes que podían suponer un impulso, aunque como en el caso de Goebbels o Hitler ese impulso tuviese unos fines perversos y unas consecuencias imprevisibles. Era un periodismo interpretativo, construido desde la información y la explicación de la actualidad política, que se basaba en su capacidad de observación.

\section{6. "El pobrecito Negus", en Ahora, 29, 30 y 31/V/1936}

Dentro de ese binomio entre actualidad política nacional e internacional, Chaves siguió fijándose en personajes llamativos, dignos de ser retratados. Así, recogió la llegada a El Peñón de Gibraltar del emperador de Etiopía, Haile Selassie, en tres crónicas para el diario Ahora firmadas durante tres días seguidos, del 29 al 31 de mayo de 1936. Los textos se titularon "El pobrecito Negus", "El Negus en el balcón de Europa" y "Una entrevista con el Negus".

Negus era para Chaves "ese imponente personaje de tan retumbantes títulos, que se permite vestir de una manera tan estrafalaria" y "un buen señor al que han expulsado de sus dominios" 29 . El periodista recurrió a la prosopografía y a la etopeya para mostrar en sus textos a un emperador

triste y solemne. Parece mentira que siendo tan poquita cosa y viniendo tan atropellado como viene a Europa se pueda andar con tanto aire de solemnidad. Es acaso la excesiva lentitud en el ademán, la hierática compostura del rostro; no sé; es algo indefinible que hace a los personajes orientales mucho más personajes que los de Occidente, aun en la desgracia ${ }^{30}$.

Tal vez, al ser testigo de cómo llega y baja las escaleras, lo presentó según el modo natural en el que se nos presentan las personas, primero en su aspecto, luego en sus gestos, después en sus palabras. A la vez, Chaves singularizaba al Negus a través de su grandeza imperial: "Aquel hombre triste resultó ser un emperador de verdad. Probablemente no recuperará jamás su Imperio; pero este hombre se morirá siendo emperador" 31 . El Negus ya no era emperador, estaba en el destierro, pero había algo en su porte solemne, pese a no ejercer el poder, que le hace especial.

Las primeras horas del Negus en Europa sirven a Chaves para, a través de su descripción, recordar la historia guerrera del pueblo etíope, algo, como ya se ha dicho, recurrente en sus caracterizaciones, la combinación del personaje con las circunstancias históricas para situarlo en su contexto:

\footnotetext{
29 CHAVES NOGALES, Manuel. "El pobrecito Negus”. En: Ahora, 29 de mayo de 1936.

${ }^{30}$ CHAVES NOGALES, Manuel. "El Negus en el balcón de Europa". En: Ahora, 30 de mayo de 1936.

${ }^{31}$ Ibídem.
} 
Mano sobre mano, los ojos muy abiertos, la mirada perdida, el Negus, inmóvil como una estatua, ha estado viendo cómo se ponía el sol y cómo se encendían las mil lucecitas de una verbena que ahora empieza a crepitar sus pies con sus organillos y sus altavoces, que ya le zumbarán en sus oídos durante toda la noche [...], ¿piensa acaso el Negus en el otro mundo bárbaro y fuerte que le creó, en los festines de carne cruda que daba a sus guerreros en el palacio imperial ${ }^{32}$.

En ese especular sobre las preocupaciones es donde Chaves se acerca al precipicio de la ficción. Lo salva, aunque tal vez no soportaría el examen de un buen editor en la actualidad, el que siempre acompañe estas cavilaciones con la escena o la estampa concreta que le ha llevado a esa interpretación y que se centre en las declaraciones y no caiga en la tentación del monólogo interior. El periodista se pone en el lugar de los hombre que retrata. Se detiene en la actitud y los gestos del Negus para interpretar el porqué de sus acciones y especular sobre sus preocupaciones. Para confirmar estas hipótesis, Chaves logró acceder al Negus y obtener unas declaraciones en las que no se incluían temas políticos, pues a esas cuestiones contestaría por medio de su secretario y por escrito. "Esta entrevista insustancial, a base de palabras corteses y de banalidades, nos ha permitido, sin embargo, darnos cuenta -creo que bastante exacta- de lo que es el rey de reyes" ${ }^{33}$. Y eso es, de hecho, lo que Chaves buscaba al acercarse a sus personajes, mostrarlos tal y como eran. Y, ¿cómo era entonces el Negus en ese momento? El narrador apelaba a su autoridad para sentenciar que era "una pavesa. Una pavesita humana que está a punto de consumirse, devorada por un fuego interior de odio, impotencia y anhelos de venganza que por instantes se asoma a los ojos en una terrible llamarada" ${ }^{34}$. El periodista usa una metáfora para describir al emperador, para mostrar la realidad de manera exacta.

Es el trato cercano, la visión del personaje desde cerca y desde dentro, lo que permite a Chaves emitir juicios más exactos y certeros. Desde fuera, al observar su llegada, podía hablar de la impresión que producía; tras hablar con él, puede asegurar de primera mano que sus percepciones no iban desencaminadas, que Haile Selassie conservaba "una indiscutible majestad, una soberanía interior indestructible [...]. Será siempre él"35.

Este texto muestra, por todo ello, tres de los elementos comunes que Chaves utiliza a la hora de caracterizar a sus personajes, tal y como se deduce de sus descripciones en prensa: en primer lugar, la influencia del ambiente entendido en un sentido amplio, el contexto histórico y las circunstancias de cada personaje; en segundo lugar, el contacto con los personajes, a los que Chaves deja hablar y a los que muestra en acción para que a través de sus actos se definan, y, por último, la presencia del periodista que a través de su experiencia personal reseña lo que ve con una finalidad de comprender e interpretar.

\footnotetext{
${ }^{32}$ Ibídem.

${ }^{33}$ CHAVES NOGALES, Manuel. "Una entrevista con el Negus". En: Ahora, 31 de mayo de 1936.

${ }^{34}$ Ibídem.

${ }^{35}$ Ibídem.
} 


\section{Conclusiones}

El análisis de la manera en que desde el periodismo Chaves retrata a los protagonistas de las noticias muestra que, para él, la comprensión de la realidad social y de la historia pasa por entender a sus protagonistas. Las conclusiones generales tras el análisis son:

1. En el caso de Chaves se debe hablar de retratos y no de semblanzas. Lo más llamativo de su caracterización se encuentra en la capacidad de retratar con una pincelada sin caer por eso en la caricatura o en la simplificación. Su "arte de la caracterización" dentro de la crónica, la entrevista o el reportaje sigue un patrón. En primer lugar, conocía al personaje y lo trataba en la medida de la posible mediante una entrevista; en segundo lugar, explicaba el momento histórico, social o político en el que el protagonista se desenvuelve para situar su posible forma de actuar en su contexto; y, en tercer lugar, mostraba a los personajes en acción en sus espacios, reseñando sus intenciones y sobre todo sus acciones para que, a través de ellos, el lector pudiese captar su carácter.

2. Una de los rasgos de la maestría de Chaves como periodista y como narrador es que los testimonios con los que conforma los textos periodísticos son voces a cuya vida y carácter se asoma. Y lo hace trazando un retrato de ellos que favorecen una comprensión más profunda de la realidad que quiere contar. Los sentimientos y contradicciones de las personas -más allá de lo que dicen- reflejan esa realidad, a veces heroica -aviadores-, a veces absurda y temible -el nazismo-.

3. A partir de la prosopografía y recurriendo a metáforas -del emperador dirá que es una pavesa - o símiles -a Hitler lo retrata como "pintorcillo de puertas" y como "un señor con gabardina que no acierta pintar un cuadro" -, Chaves busca el rasgo o los rasgos principales de los personajes, según el contexto y las necesidades informativas. El olfato periodístico del autor y la actualidad de los protagonistas y los temas están presentes en todos ellos. Se centra en los aspectos del carácter del personaje que más le llaman la atención o ahonda en las cuestiones de actualidad que son también de su interés como periodista y que pueden serlo para el lector. Tal vez por la celeridad que el oficio periodístico exige o por la capacidad misma de Chaves, en sus textos destaca su habilidad para seleccionar el rasgo que mejor define las personas que aparecen en sus reportajes y artículos. Una habilidad que se fue desarrollando con los años hacia un mayor sincretismo, como se observa en la serie de textos aquí analizados.

4. Confirmando la hipótesis de partida, en el análisis se observa que, para Chaves, contar la realidad es contarla a través de los ojos de quienes la están viviendo y eso exige del periodista ser testigo, ir a los lugares, 
hablar con las personas y sobre ese entramado hacerse cargo y escribir, no lo dictado, como le impone Goebbels, sino lo que la sociedad necesitaba saber en ese momento. La aspiración del periodista de andar y contar la realidad que observaba se fundamenta en la empatía y en la valentía, en su capacidad para ponerse en el lugar de quien retrata en algunos casos o en el de los lectores en otros.

5. En una segunda navegación, se puede decir que Chaves, a través de la selección de los personajes, se está definiendo de manera indirecta y está relatando su visión del mundo. Manteniendo el tono periodístico, se acercaba a personajes que le permitían hablar de sus intereses políticos y sociales, que le aseguraban defender una forma liberal de ver la vida, y que podían servir como ejemplo para cuestiones de actualidad. Una forma de entender el periodismo que se muestra hoy tan necesaria como en su época.

\section{Referencias bibliográficas}

CARABIAS, Josefina (1969). Epílogo: Lo que fue de aquellos dos hombres. En CHAVES NOGALES, Manuel. Juan Belmonte, matador de toros. Madrid: Alianza, pp. 321-338.

CELMA VALERO, María Pilar (1999). Caras y máscaras de 1900. Siluetas literarias. Valladolid: Editorial Difácil.

CHAVES NOGALES, Manuel (1925). Conceptos de periodismo. En: Heraldo de Madrid, 19 de mayo.

CHAVES NOGALES, Manuel (1929). De periodismo. Los errores tradicionales sobre la profesión. En: Heraldo de Madrid, 20 de septiembre.

CHAVES NOGALES, Manuel (2000). A sangre y fuego. Héroes, bestias y mártires de España. Madrid: Espasa Calpe.

CINTAS, María Isabel (2001). Un liberal ante la Revolución. Cuatro reportajes de Manuel Chaves Nogales. Sevilla: Secretariado de Publicaciones de la Universidad de Sevilla.

DE ROSENDO, Belén (2010). El perfil periodístico. Claves para caracterizar a las personas en prensa. Madrid: Tecnos.

DOSSEL, François (2007). El arte de la biografía: entre historia y ficción. México D.F.: Universidad Iberoamericana.

GÓMEZ BACEIREDO, Beatriz (2011). Primeros pasos de la biografía como género periodístico en España: tipología y características de los textos biográficos en La Ilustración. En: Comunicación y Sociedad, vol. XXIV, n $^{\circ} 2$, pp. 77-130. 
KOVACH, Bill; ROSENSTIEL, Tom (2012). Los elementos del Periodismo. Madrid: Aguilar.

MARÍN, Flora; CAMINOS, José María; ARMENTIA, José Ignacio; ALBERDI, Aintzane (2003). El papel de El País y El Mundo en la creación del mito de Bin Laden. En: Zer, vol. 8, no 15, pp. 9-36.

PÉREZ, Álvaro (2013a). Manuel Chaves Nogales, periodista. En: Anagramas, vol. $11, n^{\circ} 22,2013$, pp. 131-144.

PÉREZ, Álvaro (2013b). Manuel Chaves Nogales y el Nuevo Periodismo. En: Ámbitos. Revista Internacional de Comunicación, nº 23, 2013, pp. 81-90.

PULIDO, Manuel (2009). Plutarco de moda. La biografía moderna en España (1900-1950). Mérida: Editora Regional de Extremadura.

SERRANO, Enrique (2002). Vidas oblicuas: Aspectos teóricos de la nueva biografía en España (1928-1936). Zaragoza: Prensas Universitarias de Zaragoza.

SUBERVIOLA, Daniel; TORRENTE, Luis Felipe (2013). El hombre que estuvo allí, Salamanca: Libros.com.

WEINBERG, Steve (1992). Telling the untold story: how investigative reporters are changing the craft of biography. Columbia: University of Missouri Press. 